\title{
MicroRNA-218 inhibits the migration, epithelial-mesenchymal transition and cancer stem cell properties of prostate cancer cells
}

\author{
BING GUAN, LIJUN MU, LINLIN ZHANG, KE WANG, JUANHUA TIAN, \\ SHAN XU, XINYANG WANG, DALIN HE and YUEFENG DU
}

Department of Urology, First Affiliated Hospital of Xi'an Jiaotong University, Xi'an, Shaanxi 710061, P.R. China

Received December 27, 2016; Accepted February 27, 2018

DOI: $10.3892 / \mathrm{ol} .2018 .8877$

\begin{abstract}
MicroRNA (miRNA) is a class of non-coding single-stranded RNA, able to regulate tumor-associated genes via binding the 3'-UTR of the target gene mRNA. Previous publications have demonstrated that miRNA-218 (miR-218) acts as a tumor-suppressive miRNA in various types of human cancer, including prostate cancer (PCa). However, the role of miR-218 in regulating $\mathrm{PCa}$ cell stemness and epithelial-mesenchymal transition remains unknown and requires further research. In the present study, it is demonstrated that miR-218 was downregulated in $2 \mathrm{PCa}$ cell lines and could suppress cell migration, EMT and the exhibition of cancer stem cell-like properties. The expression of GLI family zinc finger 1 (Gli1) was inhibited by miR-218 overexpression, suggesting miR-218-suppression of Glil as a potential mechanism for the tumor-suppressive effect of miR-218. Overall, the results indicate that miR-218 served a critical role in the inhibition of PCa development. This may provide new insight for elucidating the mechanisms of PCa oncogenesis and suggests that miR-218 may be a novel therapeutic target for PCa.
\end{abstract}

\section{Introduction}

Prostate cancer (PCa) is the most common form of cancer among males in developed countries, with an estimated 648,400 new cases and 136,500 mortalities in 2008 (1). Currently, androgen-deprivation therapy is a key treatment for metastatic PCa. However, many patients develop castration-resistant $\mathrm{PCa}$, which is a major cause of male mortality in developed countries (2). Further research is urgently required to develop more effective therapies for this disease.

Correspondence to: Dr Dalin He or Dr Yuefeng Du, Department of Urology, First Affiliated Hospital of Xi'an Jiaotong University, 277 Yanta West Road, Xi'an, Shaanxi 710061, P.R. China

E-mail: dalinhexjtu@163.com

E-mail: duyuefeng113@163.com

Key words: microRNA-218, prostate cancer, migration, epithelial-mesenchymal transition, cancer stem cell properties
MicroRNA (miRNA) is a class of non-coding single-stranded RNA that regulates tumor-associated genes via binding the 3'-UTR of target gene mRNA (3-5). Previous research has reported that miRNAs (miRs) serve important roles in human cancer biological processes, including initiation, development, migration and metastasis (6-8). In terms of the development of PCa, miR-34a inhibits prostate cancer stem cell (CSC) features and metastasis by directly repressing CD44 (9). Upregulation of miR-132/212 expression inhibits TGF- $\beta$-mediated epithelial-mesenchymal transition (EMT) of PCa cells by targeting SOX4 (10). Tumor-suppressive miR-29 inhibits cancer cell migration and invasion via targeting LAMC1 in PCa (11). Previous studies have also reported that miR-218 serves a tumor-suppressive role in PCa. However, the role of miR-218 in regulating $\mathrm{PCa}$ stemness and EMT remains uncharacterized.

In the present study, the expression of miR-218 in $\mathrm{PCa}$ cell lines was investigated, and the impact of miR-218 on tumor migration, EMT and CSC properties in PCa was investigated in vitro. The results demonstrate that miR-218 was downregulated in PCa cell lines and was able to suppress PCa cell migration, EMT and cancer stem cell properties. The expression of Gli1 was inhibited by miR-218 overexpression, suggesting a role for this protein in the mechanism of tumor-suppression of miR-218 in PCa. Altogether, the present study indicates that miR-218 served a critical role in inhibiting $\mathrm{PCa}$ development, providing new insights into clarifying the potential mechanisms of PCa oncogenesis and revealing that miR-218 may be a novel therapeutic target for PCa.

\section{Materials and methods}

Cell lines and cell culture. PCa cell lines LNCaP and C4-2 were obtained from the American Type Culture Collection (Manassas, VA, USA). BPH-1 cells were provided by Dr Jer-Tsong Hsieh (University of Texas Southwestern Medical Center, Dallas, TX, USA). These three cell lines were cultured in RPMI-1640 medium (Gibco; Thermo Fisher Scientific, Inc., Waltham, MA, USA) with $10 \%$ fetal bovine serum (FBS; Hyclone; GE Healthcare Life Sciences, Logan, UT, USA) in a humidified chamber at $37^{\circ} \mathrm{C}$ in $5 \% \mathrm{CO}_{2}$.

Reverse transcription-quantitative polymerase chain reaction (RT-qPCR) analysis. Total RNA was extracted from harvested 
cells using TRIzol (Thermo Fisher Scientific, Inc.) and reverse transcribed to cDNA using the miScript II RT kit (Qiagen GmbH, Hilden, Germany), according to the manufacturers' protocols. The CFX96 PCR system (Bio-Rad Laboratories, Inc., Hercules, CA, USA) with SYBR-Green PCR Master Mix (Takara Bio, Inc., Otsu, Japan) was used to detect the transcriptional expression of miR-218. The thermocycling conditions were as follows: $95^{\circ} \mathrm{C}$ for $30 \mathrm{sec}$, followed by 40 cycles at $95^{\circ} \mathrm{C}$ for $5 \mathrm{sec}$, and then $60^{\circ} \mathrm{C}$ for $30 \mathrm{sec}$. U6 was used as an internal control, and relative gene expression was calculated using the $2^{-\Delta \Delta \mathrm{Cq}}$ method (12). The primer sequences used were as follows: miR-218 forward, 5'-CGAGTGCATTTG TGCTTGATCTA-3' and reverse, 5'-TAATGGTCGAACGCC TAACGTC-3'; U6 forward, 5'-CTCGCTTCGGCAGCACA-3' and reverse, 5'-TGGTGTCGTGGAGTCG-3'.

Lentivirus transfection. LNCaP and C4-2 cells were seeded and cultured for $24 \mathrm{~h}$ and to $40-50 \%$ confluence. The lentiviral vector 3 (LV3)-miR-218, constructed by GenePharma Co., Ltd. (Shanghai, China), was used to transfect cells in an overnight incubation. LV3 scrambled lentiviral vector (LV3-NC; GenePharma Co., Ltd.) was used as a negative control. At $48 \mathrm{~h}$ after infection, the stable clones were maintained by puromycin (2-3 $\mu \mathrm{g} / \mathrm{ml}$; Sigma-Aldrich; Merck KGaA, Darmstadt, Germany)-resistant culturing.

Transwell migration assay. Complete growth medium (RPMI-1640 with $10 \%$ FBS, $1 \mathrm{ml}$ ) was added to each lower chamber as a chemoattractant. Transwell inserts with a pore diameter of $8-\mu \mathrm{m}$ were used (Millipore; Merck KGaA). Cells, suspended in serum-free medium at $5-8 \times 10^{4}$ cells $/ \mathrm{ml}$, were seeded into the upper chamber at $400 \mu \mathrm{l} /$ well. After an incubation of $20 \mathrm{~h}$, the upper surface of the insert was wiped and cells that had migrated to the lower surface were fixed using $4 \%$ paraformaldehyde for $30 \mathrm{~min}$ and stained with $0.1 \%$ crystal violet for $20 \mathrm{~min}$ at room temperature. Cell number was counted in 6 random fields per well (magnification, $\mathrm{x} 200)$.

Western blot assay. Cells were washed 3 times in PBS before the protein was extracted using radioimmunoprecipitation assay buffer [50 mM Tris (pH 8.0), $150 \mathrm{mM} \mathrm{NaCl,} \mathrm{0.1 \%} \mathrm{SDS,}$ $1 \%$ NP-40 and $0.5 \%$ sodium deoxycholate] with protease inhibitors. The concentration of protein was detected by Bradford assay protein quantitation kit (Abcam, Cambridge, UK). Proteins $(30 \mu \mathrm{g})$ were separated by $12 \%$ SDS-PAGE and transferred into nitrocellulose membranes. Following blocking in $5 \%$ skim milk at room temperature for $1 \mathrm{~h}$, the membranes were incubated with primary antibodies at $4^{\circ} \mathrm{C}$ overnight. Primary antibodies used were as follows: GAPDH (1:10,000; cat. no. KC-5G4; Kangchen Bio-tech Co., Ltd., Shanghai, China); E-cadherin (1:1,000; cat. no. sc-8426; Santa Cruz Biotechnology, Inc., Dallas, TX, USA); Vimentin (1:200; cat. no. sc-6260; Santa Cruz Biotechnology, Inc.); CD44 (1:800; cat. no. 3570; Cell Signaling Technology, Inc., Danvers, MA, USA); Oct4 (1:500; cat. no. ab18976; Abcam); Nanog (1:200; cat. no. ab21624; Abcam); and Gli1 (1:1,000; cat. no. 2643; Cell Signaling Technology, Inc.). The membranes were then washed in Tris-buffered saline with $0.1 \%$ Tween and incubated with horseradish peroxidase-conjugated secondary antibodies [goat anti-rabbit $\operatorname{IgG}(1: 2,000$; cat. no. ZB-2301); and goat anti-mouse IgG (1:2,000; cat. no. ZB-2305) (all from OriGene Technologies, Inc., Beijing, China) for $1 \mathrm{~h}$ at room temperature. Protein bands were visualized using a Molecular Imager ChemiDoc XRS System (Bio-Rad Laboratories).

Colony-forming and tumor sphere formation assays. For the colony-forming assay, $2 \times 10^{3}$ cells were seeded into each well of a 6-well plate and incubated for 10-14 days. Following 3 washes in PBS, cells were fixed using 4\% paraformaldehyde for $30 \mathrm{~min}$ at room temperature and stained with $0.1 \%$ crystal violet for $20 \mathrm{~min}$ at room temperature. The tumor sphere formation assay was performed by seeding $1 \times 10^{4}$ cells to each well of low-adhesion 6-well plate in serum-free Dulbecco's modified Eagle/F12 medium supplemented with $20 \mathrm{ng} / \mathrm{ml}$ epidermal growth factor, $10 \mathrm{ng} / \mathrm{ml}$ basic fibroblast growth factor and 2\% B27 (all Invitrogen; Thermo Fisher Scientific, Inc.). After 2 weeks, plates were analyzed for tumor sphere formation using an inverted microscope (magnification, x200).

Statistical analysis. All statistical analysis was performed using GraphPad Prism version 6.0 (GraphPad Software, Inc., La Jolla, CA, USA). Differences between 2 groups were compared using the Student's t-test. For comparisons of $\geq 3$ groups, one-way analysis of variance followed by Tukey's post hoc test was used. $\mathrm{P}<0.05$ was considered to indicate a statistically significant difference.

\section{Results}

miR-218 expression is downregulated in PCa cells. RT-qPCR was performed to compare the expression of miR-218 in $\mathrm{PCa}$ cells with that in healthy prostate epithelial cells. This revealed that the expression of miR-218 was notably downregulated in PCa cell lines, LNCaP and C4-2, compared with the normal prostate epithelial cells (BPH-1; Fig. 1A).

Construction of miR-218-overexpressing PCa cells. In order to reveal the effects of miR-218 on PCa migration, EMT and CSC properties, miR-218-overexpressing LNCaP/C4-2 cells were constructed by transfecting the cells with LV3-miR-218 lentiviral vectors. Subsequently, cells were analyzed by RT-qPCR to confirm miR-218-overexpression (Fig. 1B).

Overexpression of miR-218 inhibits $P C$ a cell migration and $E M T$. The Transwell migration assays demonstrated that the migration of LNCaP/C4-2 cells was suppressed by miR-218 overexpression (Fig. 2). Western blotting of EMT markers demonstrated that miR-218 overexpression caused a slight increase in the expression of E-cadherin and a significant decrease in the expression of vimentin (Fig. 3A). These results suggest that overexpression of miR-218 inhibits PCa cell migration and EMT.

Overexpression of miR-218 diminishes PCa cell stemness properties. Protein expression profiling of cancer stemness markers was performed by westernblotting. The results indicate that overexpression of miR-218 downregulated the expression of CD44, Oct4 and Nanog (Fig. 3B). Colony forming assays were performed to assess the self-renewal capacity of PCa 
A

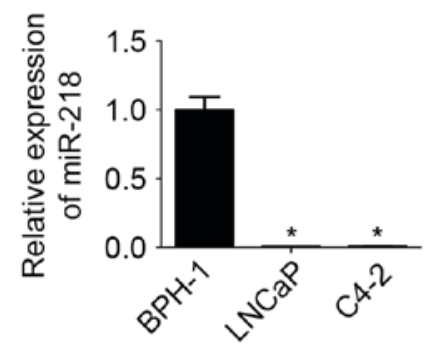

B

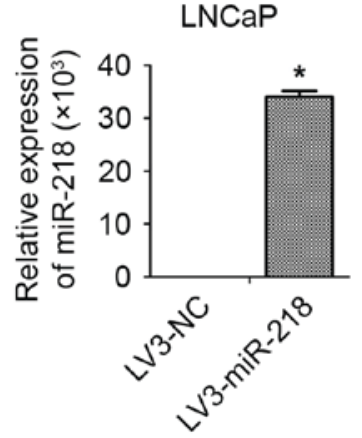

C4-2

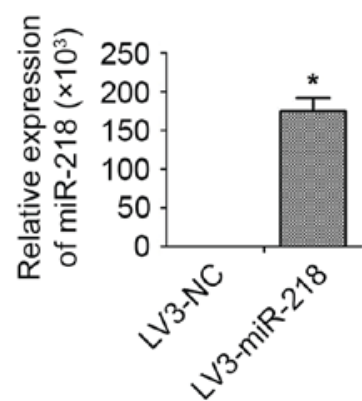

Figure 1. The expression of miR-218 in prostate cancer cells and construction of miR-218 overexpressing prostate cancer cells. (A) reverse transcription-quantitative polymerase chain reaction analysis (normalized using U6) demonstrates the significant downregulation of miR-218 expression in prostate cancer cells compared with the 'normal' prostate epithelial cells. " $\mathrm{P}<0.05 \mathrm{vs}$. BPH-1. (B) Validation of the miR-218-overexpressing prostate cancer cell lines. These data are representative of 3independent experiments. ${ }^{*} \mathrm{P}<0.05$ vs. control. miR-218, microRNA-218.

A

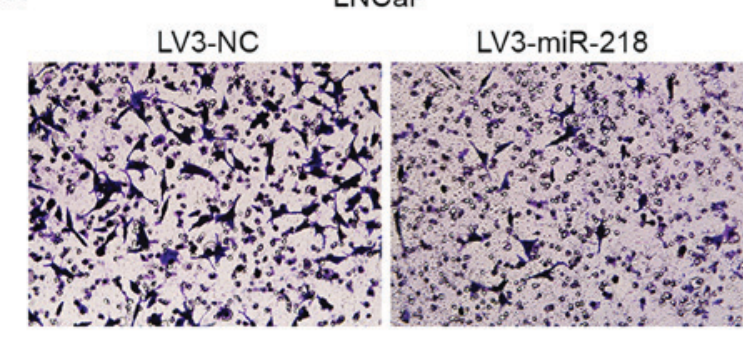

B

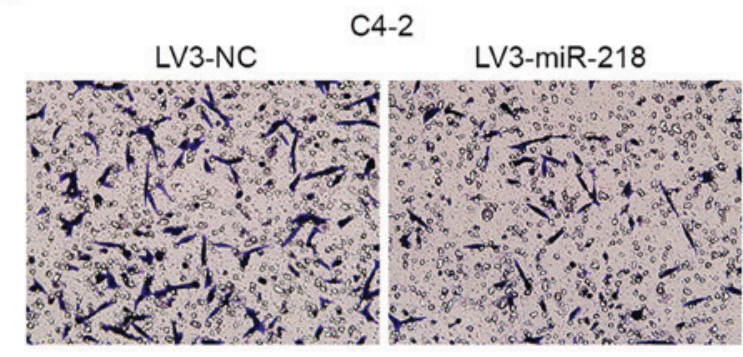

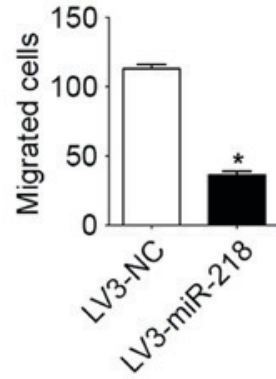

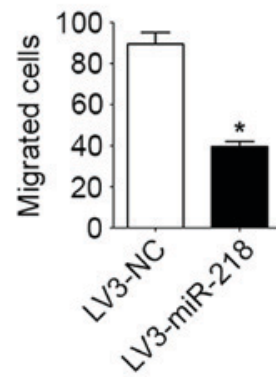

Figure 2. The effects of miR-218 on the migratory capability of prostate cancer cells. (A) The migration of LNCaP cells was suppressed by miR-218 overexpression. (B) A similar result was observed of $\mathrm{C} 4-2$ cells. These data are representative of 3 independent experiments (magnification, $\mathrm{x} 200$ ). "P<0.05 vs. LV3-NC. miR-218, microRNA-218; LV3, lentivirus vector 3; NC, negative control.

cells. It was demonstrated that the miR-218-overexpressing $\mathrm{LNCaP}$ cells formed fewer and smaller colonies than the control cells (Fig. 4A). Similar results were obtained from the clonogenic assay performed in C4-2 cells (Fig. 4B), indicating that miR-218 may serve a critical role in tumor growth inhibition. The tumor sphere formation assay is well established for measuring the self-renewing capability of stem cells. In these experiments, the control cells generated more tumor-spheres than the miR-218-overexpressing cells in both cell lines (Fig. 4C and D). Therefore, these results suggest that overexpression of miR-218 diminished PCa cell stemness properties.

Glil expression is downregulated by miR-218 overexpression. Numerous studies have indicated that the Hedehog-Gli signaling pathway serves a critical role in cancer cell EMT occurrence and CSC generation (13-15). In the preset study, western blot analysis indicated that the expression of Gli1 was inhibited by miR-218 overexpression (Fig. 5), indicating that miR-218 suppression of Gli1 may be a mechanism for the anticancer effect of miR-218 in PCa.

\section{Discussion}

Advances have been made in PCa diagnosis and treatment in recent years (16). However, management of PCa remains a challenge. It has been widely reported that EMT and CSCs are critical for cancer initiation and development (17-21). However, the molecular mechanisms by which EMT and CSCs execute their effects require further investigation. 
A

E-cadherin
Vimentin
GAPDH

C4-2

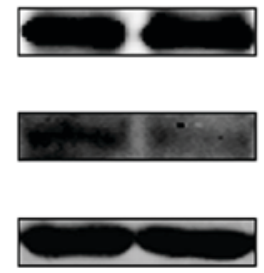

LV3-NC LV3-miR-218
B

CD44

Oct 4

Nanog

GAPDH
C4-2
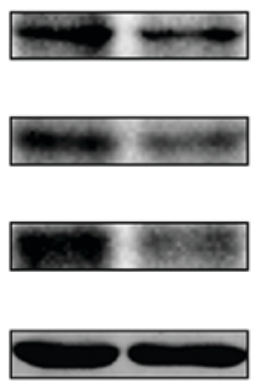

LV3-NC LV3-miR-218

Figure 3. Effects of miR-218 on epithelial-mesenchymal transition and cancer stem cell biomarker expression in prostate cancer cells. (A) Western blot analysis revealed that the overexpression of miR-218 increased the expression of E-cadherin and decreased the expression of Vimentin (EMT biomarkers markers). (B) Western blot analysis also revealed that the overexpression of miR-218 downregulated the expression of cluster of differentiation 44, octamer-binding protein 4 and Nanog (stemness biomarkers). These data are representative of 3 independent experiments and GADPH was used as a loading control. miR-218, microRNA-218; LV3, lentivirus vector 3; NC, negative control; CD44, cluster of differentiation 44; Oct 4, octamer-binding protein 4.

A

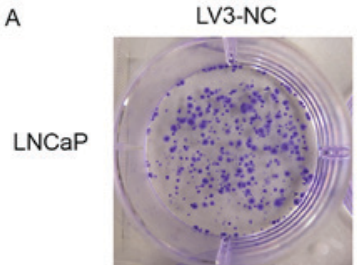

B

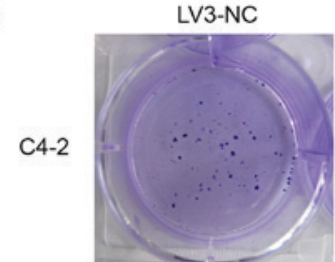

C

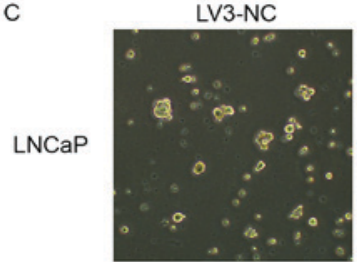

D

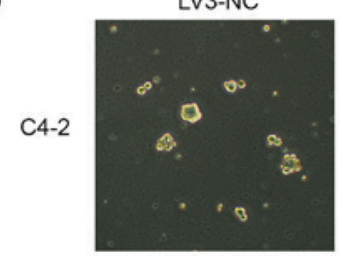

LV3-miR-218

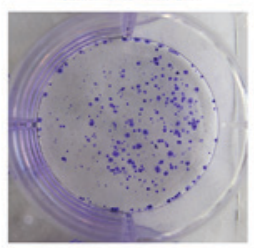

LV3-miR-218

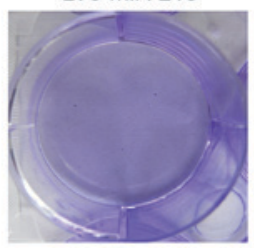

LV3-miR-218

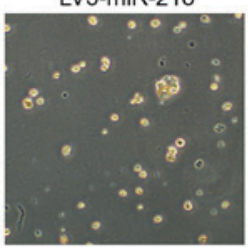

LV3-miR-218

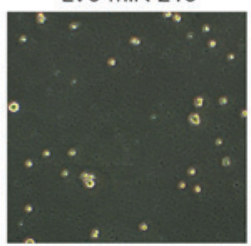

Figure 4. Overexpression of miR-218 suppressed the growth and self-renewal capacities of prostate cancer cells. (A) In colony-forming assays, LNCaP-LV3-miR-218 cells formed fewer and smaller colonies compared with LV3-NC control cells. (B) A similar observation was made of C4-2 cells. (C) Tumor sphere formation assay was used to measure the self-renewing ability of cells. The LV3-NC control cells generated more tumor-spheres than LV3-miR-218 cells in LNCaP cells and (D) C4-2 cells (magnification, x200). These data are representative of 3 independent experiments. miR-218, microRNA-218; LV3, lentivirus vector 3; NC, negative control.

Previous studies have demonstrated that miRNAs serve important roles in human cancer biological processes, including initiation, development, migration and metastasis (22-26). miR-218 can act as a tumor suppressor and is downregulated

A

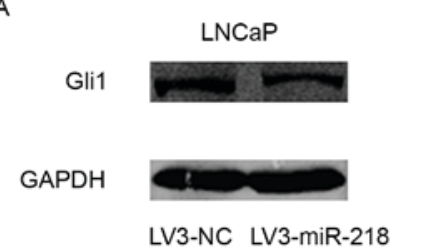

B

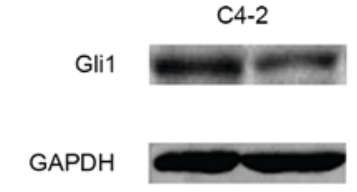

LV3-NC LV3-miR-218

Figure 5. Western blot analysis demonstrated that overexpression of miR-218 reduced the protein expression of Gli1 in (A) LNCaP cells and (B) in C4-2 cells. These data are representative of 3 independent experiments. miR-218, microRNA-218; Gli1, Gli family zinc finger 1; LV3, lentivirus vector 3; $\mathrm{NC}$, negative control.

in various types of human cancer (27-31). miR-218 can inhibit cancer cell proliferation, invasion, migration, EMT, lymph node metastasis and self-renewal in glioma, cervical cancer, gastric cancer and bladder cancer, among others (32-36). One study indicated that miR-218 expression is decreased in $\mathrm{PCa}$, and impedes IL-6-induced PCa cell proliferation and invasion via suppression of LGR4 expression (37). miR-218 has also been demonstrated to inhibit PCa cell growth and promote apoptosis by repressing TPD52 expression (38), as well as inhibit PCa cell migration and invasion via targeting LASP1 (39). We hypothesize that miR-218 may also inhibit PCa cell migration, EMT and CSC properties. However, the underlying role of miR-218 in regulating PCa stemness maintenance and EMT is poorly characterized at present.

In the present study, the expression of miR-218 was notably downregulated in PCa cells and the $\mathrm{LNCaP} / \mathrm{C} 4-2$ cell constructs overexpressing miR-218 indicated that miR-218 inhibited PCa cell migration. Results of western blotting revealed that the overexpression of miR-218 downregulated the expression of vimentin, CD44, Oct4 and Nanog. In colony-forming assays, miR-218-overexpressing cells formed fewer and smaller colonies than the control cells. Consistently, the control cells generated more tumor-spheres than miR-218-overexpressing cells, suggesting that overexpression of miR-218 inhibited PCa stemness properties. Copious evidence has indicated that the Hedgehog-Gli signaling pathway serves a critical role in cancer cell EMT and CSC generation $(13-15,40)$. In the present study, the expression of Gli1 was inhibited by miR-218 
overexpression. This indicates that miR-218 suppression of Gli1 may serve in the mechanism by which miR-218 inhibits EMT and stemness maintenance in PCa.

The regulatory mechanisms of human CSC maintenance and EMT are very complex. If miR-218 targets Gli1 by binding its 3'-UTR, or other molecular mediators between miR-218 and Gli1, the mechanism requires further investigation. In conclusion, the present study indicates that miR-218 served a critical role in inhibiting the migration, EMT and CSC properties of PCa cells. This provides a new insight for clarifying the potential mechanisms of $\mathrm{PCa}$ oncogenesis, and indicates that miR-218 may be a potential therapeutic target for PCa.

\section{Acknowledgements}

Not applicable.

\section{Funding}

The present study was supported by the National Natural Science Foundation of China, (grant nos., 81372736 and 81272811) awarded to YD and LZ, respectively.

\section{Availability of data and materials}

All data generated or analyzed during this study are included in this published article.

\section{Authors' contributions}

YD and DH designed and supervised all experiments and contributed to the manuscript preparation. BG performed the experiments, analyzed the data and contributed to the manuscript preparation. LM and JT contributed to the cell culture and lentivirus transfection. $\mathrm{LZ}$ and $\mathrm{KW}$ contributed to the data analysis. SX and XW contributed to western blot assay and manuscript preparation.

\section{Ethics approval and consent to participate}

Not applicable.

\section{Consent for publication}

Not applicable.

\section{Competing interests}

The authors declare that they have no competing interests.

\section{References}

1. Jemal A, Bray F, Center MM, Ferlay J, Ward E and Forman D: Global cancer statistics. CA Cancer J Clin 61: 69-90, 2011.

2. Egan A, Dong Y, Zhang H, Qi Y, Balk SP and Sartor O: Castration-resistant prostate cancer: Adaptive responses in the androgen axis. Cancer Treat Rev 40: 426-433, 2014.

3. Bartel DP: MicroRNAs: Genomics, biogenesis, mechanism, and function. Cell 116: 281-297, 2004.

4. Lim LP, Lau NC, Garrett-Engele P, Grimson A, Schelter JM, Castle J, Bartel DP, Linsley PS and Johnson JM: Microarray analysis shows that some microRNAs downregulate large numbers of target mRNAs. Nature 433: 769-773, 2005.
5. Guo H, Ingolia NT, Weissman JS and Bartel DP: Mammalian microRNAs predominantly act to decrease target mRNA levels. Nature 466: 835-840, 2010.

6. Iorio MV and Croce CM: MicroRNAs in cancer: Small molecules with a huge impact. J Clin Oncol 27: 5848-5856, 2009.

7. Iorio MV, Ferracin M, Liu CG, Veronese A, Spizzo R, Sabbioni S, Magri E, Pedriali M, Fabbri M, Campiglio M, et al: MicroRNA gene expression deregulation in human breast cancer. Cancer Res 65: 7065-7070, 2005.

8. Zhang X, Tang J, Zhi X, Xie K, Wang W, Li Z, Zhu Y, Yang L, $\mathrm{Xu} \mathrm{H}$ and $\mathrm{Xu} \mathrm{Z}$ : miR-874 functions as a tumor suppressor by inhibiting angiogenesis through STAT3/VEGF-A pathway in gastric cancer. Oncotarget 6: 1605-1617, 2015.

9. Liu C, Kelnar K, Liu B, Chen X, Calhoun-Davis T, Li H, Patrawala L, Yan H, Jeter C, Honorio S, et al: The microRNA miR-34a inhibits prostate cancer stem cells and metastasis by directly repressing CD44. Nat Med 17: 211-215, 2011.

10. Fu W, Tao T, Qi M, Wang L, Hu J, Li X, Xing N, Du R and Han B: MicroRNA-132/212 upregulation inhibits TGF- $\beta$-mediated epithelial-mesenchymal transition of prostate cancer cells by targeting SOX4. Prostate 76: 1560-1570, 2016.

11. Nishikawa R, Goto Y, Kojima S, Enokida H, Chiyomaru T, Kinoshita T, Sakamoto S, Fuse M, Nakagawa M, Naya Y, et al: Tumor-suppressive microRNA-29s inhibit cancer cell migration and invasion via targeting LAMC1 in prostate cancer. Int J Oncol 45: 401-410, 2014.

12. Livak KJ and Schmittgen TD: Analysis of relative gene expression data using real-time quantitative PCR and the 2(-delta delta C(T)) method. Methods 25: 402-408, 2001.

13. Xu X, Su B, Xie C, Wei S, Zhou Y, Liu H, Dai W, Cheng P, Wang F, Xu X and Guo C: Sonic hedgehog-Gli1 signaling pathway regulates the epithelial mesenchymal transition (EMT) by mediating a new target gene, S100A4, in pancreatic cancer cells. PLoS One 9: e96441, 2014.

14. Takebe N, Harris PJ, Warren RQ and Ivy SP: Targeting cancer stem cells by inhibiting Wnt, Notch, and Hedgehog pathways. Nat Rev Clin Oncol 8: 97-106, 2011.

15. Clement V, Sanchez P, de Tribolet N, Radovanovic I and Ruiz i Altaba A: HEDGEHOG-GLI1 signaling regulates human glioma growth, cancer stem cell self-renewal, and tumorigenicity. Curr Biol 17: 165-172, 2007.

16. Ahmed A, Ali S and Sarkar FH: Advances in androgen receptor targeted therapy for prostate cancer. J Cell Physiol 229: 271-276, 2014.

17. Brabletz T, Jung A, Spaderna S, Hlubek F and Kirchner T: Opinion: Migrating cancer stem cells-an integrated concept of malignant tumour progression. Nat Rev Cancer 5: 744-749, 2005.

18. Deshmukh A, Deshpande K, Arfuso F, Newsholme P and Dharmarajan A: Cancer stem cell metabolism: A potential target for cancer therapy. Mol Cancer 15: 69, 2016.

19. Colak S and Medema JP: Cancer stem cells-important players in tumor therapy resistance. FEBS J 281: 4779-4791, 2014.

20. Thiery JP, Acloque H, Huang RY and Nieto MA: Epithelial-mesenchymal transitions in development and disease. Cell 139: 871-890, 2009.

21. Dave B, Mittal V, Tan NM and Chang JC: Epithelial-mesenchymal transition, cancer stem cells and treatment resistance. Breast Cancer Res 14: 202, 2012.

22. Miska EA: How microRNAs control cell division, differentiation and death. Curr Opin Genet Dev 15: 563-568, 2005.

23. Garzon R, Marcucci G and Croce CM: Targeting microRNAs in cancer: Rationale, strategies and challenges. Nat Rev Drug Discov 9: 775-789, 2010.

24. Li X, Yu Z, Li Y, Liu S, Gao C, Hou X, Yao R and Cui L: The tumor suppressor miR-124 inhibits cell proliferation by targeting STAT3 and functions as a prognostic marker for postoperative NSCLC patients. Int J Oncol 46: 798-808, 2015.

25. Zheng Z, Ding M, Ni J, Song D, Huang J and Wang J: MiR-142 acts as a tumor suppressor in osteosarcoma cell lines by targeting Rac1. Oncol Rep 33: 1291-1299, 2015.

26. Zhou N, Fei D, Zong S, Zhang M and Yue Y: MicroRNA-138 inhibits proliferation, migration and invasion through targeting hTERT in cervical cancer. Oncol Lett 12: 3633-3639, 2016.

27. Davidson MR, Larsen JE, Yang IA, Hayward NK, Clarke BE, Duhig EE, Passmore LH, Bowman RV and Fong KM: MicroRNA-218 is deleted and downregulated in lung squamous cell carcinoma. PLoS One 5: e12560, 2010.

28. Yu H, Gao G, Jiang L, Guo L, Lin M, Jiao X, Jia W and Huang J: Decreased expression of miR-218 is associated with poor prognosis in patients with colorectal cancer. Int J Clin Exp Pathol 6: 2904-2911, 2013. 
29. Guan H, Wei G, Wu J, Fang D, Liao Z, Xiao H, Li M and Li Y: Down-regulation of miR-218-2 and its host gene SLIT3 cooperate to promote invasion and progression of thyroid cancer. J Clin Endocrinol Metab 98: E1334-E1344, 2013.

30. Wang XX, Ge SJ, Wang XL, Jiang LX, Sheng MF and Ma JJ: miR-218 tissue expression level is associated with aggressive progression of gastric cancer. Genet Mol Res 15, 2016.

31. Wang HT, Liu AG, Luo DS, Zhou ZN, Lin HG, Chen RZ, He JS and Chen K: miR-218 expression in osteosarcoma tissues and its effect on cell growth in osteosarcoma cells. Asian Pac J Trop Med 7: 1000-1004, 2014

32. Wang G, Fu Y, Liu G, Ye Y and Zhang X: miR-218 inhibits proliferation, migration, and EMT of gastric cancer cells by targeting WASF3. Oncol Res 25: 355-364, 2016.

33. Jiang Z, Song Q, Zeng R, Li J, Li J, Lin X, Chen X, Zhang J and Zheng Y: MicroRNA-218 inhibits EMT, migration and invasion by targeting SFMBT1 and DCUN1D1 in cervical cancer. Oncotarget 7: 45622-45636, 2016

34. Tu Y, Gao X, Li G, Fu H, Cui D, Liu H, Jin W and Zhang Y: MicroRNA-218 inhibits glioma invasion, migration, proliferation, and cancer stem-like cell self-renewal by targeting the polycomb group gene Bmil. Cancer Res 73: 6046-6055, 2013.

35. Kogo R, How C, Chaudary N, Bruce J, Shi W, Hill RP, Zahedi P, Yip KW and Liu FF: The microRNA-218 Survivin axis regulates migration, invasion, and lymph node metastasis in cervical cancer. Oncotarget 6: 1090-1100, 2015.
36. Cheng Y, Yang X, Deng X, Zhang X, Li P, Tao J and Lu Q: MicroRNA-218 inhibits bladder cancer cell proliferation, migration, and invasion by targeting BMI-1. Tumour Biol 36: 8015-8023, 2015.

37. Li F, Gu C, Tian F, Jia Z, Meng Z, Ding Y and Yang J: MiR-218 impedes IL-6-induced prostate cancer cell proliferation and invasion via suppression of LGR4 expression. Oncol Rep 35: 2859-2865, 2016.

38. Han G, Fan M and Zhang X: MicroRNA-218 inhibits prostate cancer cell growth and promotes apoptosis by repressing TPD52 expression. Biochem Biophys Res Commun 456: 804-809, 2015.

39. Nishikawa R, Goto Y, Sakamoto S, Chiyomaru T, Enokida H, Kojima S, Kinoshita T, Yamamoto N, Nakagawa M, Naya Y, et al: Tumor-suppressive microRNA-218 inhibits cancer cell migration and invasion via targeting of LASP1 in prostate cancer. Cancer Sci 105: 802-811, 2014.

40. Inaguma S, Kasai K, Hashimoto $M$ and Ikeda H: GLI1 modulates EMT in pancreatic cancer-letter. Cancer Res 72: 3702-3703, 3704-3705, 2012 